\title{
0 Telejornal sob o olhar da cenografia: Da experimentação à imagem de marca*
}

Maria do Rosário Saraiva, Luciana Fernandes, José Azevedo**

\section{Resumo}

Os 50 anos do Telejornal servem de pano de fundo à análise da evolução da cenografia de informação televisiva em Portugal. Após 35 anos de exclusividade como ritual quotidiano, o Telejornal viu entrar em cena novos concorrentes: O Jornal da Noite (SIC) e o Jornal Nacional (TVI). Na procura da diferenciação e da sedução dos telespectadores - motivadas pela concorrência -, as três televisões experimentam cenografias e tecnologias, inovaram nos materiais empregues e nos ambientes instalados ou na abertura para as redacções. Os elementos gráficos invadem os ecrãs dos televisores. Através da análise comparativa das cenografias destes três espaços noticiosos, apresentam-se as principais características de cada um, as intenções comunicacionais subjacentes e a relação com o público. Serão igualmente discutidas as implicações destas transformações no processo de informação pelos telespectadores.

Palavras-chave: televisão, informação, Telejornal, cenografia.

Telejornal é um termo que, no cenário português, pertence ao canal público, a RTP, desde 1959, o que o torna no "programa mais antigo da televisão portuguesa» (Mendes, Santos Silva \& Marques, 2007, Março 3). Porém, a generalização do nome aos outros canais pelo senso comum é um facto constatado, evidenciado pelas definições dadas por vários dicionários:

\footnotetext{
* Este artigo dá conta da primeira fase do projecto de investigação "A cenografia da informação televisiva em Portugal: da sobriedade à espectacularidade das redacções” (projecto PTDC/CCI/71951/2006, financiado), cujo corpus de análise se centra nos noticiários das $20 \mathrm{~h} 00$ dos três canais generalistas portugueses.

** M. R. Saraiva, Investigadora do CETAC.media e coordenadora do projecto. L. Fernandes, Bolseira de Investigação. J. Azevedo, Professor Associado, Departamento de Sociologia da Faculdade de Letras da Universidade do Porto.
} 
Telejornal: Espaço dedicado por uma estação de televisão para apresentação de peças de carácter informativo. $\mathrm{O}$ actual e generalizado modelo de telejornal, conduzido por um pivot de informação, foi inaugurado na década de 50 pela BBC, no Reino Unido, e pelas cadeias televisivas, nos Estados Unidos. (Diciopédia, 2008)

Noticiário transmitido pela televisão, em que geralmente se abordam os acontecimentos do dia. (Dicionário Houaiss da Língua Portuguesa, 2005)

Usualmente, em Portugal, designa o jornal das 20h00, conhecido na linguagem televisiva como horário nobre. Todos os dias, às 20h00, na maioria ${ }^{1}$ das casas portuguesas, a televisão está pronta para os noticiários e, após os genéricos, começa o espectáculo! Estão lá o(s) pivot(s), o logótipo da estação, a mesa, o oráculo, o ticker ${ }^{2}$, o pictograma e ainda, como background, a redacção em funcionamento. Para trás ficam 50 anos de história de Telejornal que merecem ser contados, sob a perspectiva dos seus aspectos cenográficos, sem ignorar os jornais televisivos das estações de televisão privadas: Jornal da Noite e Jornal Nacional. Mas qual é a especificidade da cenografia de informação? Designa o conjunto de dispositivos reunidos para criar um cenário para transmissão dos noticiários em televisão ${ }^{3}$. Para além do cenário físico, integra também os dispositivos audiovisuais e grafismos e, mais recentemente, a cenografia virtual.

A abordagem aqui proposta permite, ao centrar o olhar do observador sobre a forma mais do que sobre o conteúdo da informação televisiva, analisar questões específicas do meio audiovisual e da própria produção da notícia em televisão que é o contexto de produção. Este contexto é constituído pelo conjunto: espaço cenografado (incluindo dispositivos tecnológicos) + pivots, realizador e operadores de câmara. A este contexto in situ, juntam-se os elementos gráficos (transparências, iconografia, janelas electrónicas, grafismo, etc.) e a cenografia virtual inseridos na imagem e percepcionados pelo telespectador no ecrã e, como tal, assimilados como parte integrante desse contexto da notícia pelo telespectador. O conjunto dos elementos assim veiculados durante a emissão do noticiário ou, se quisermos, a aparência que assume este contexto de produção perante o olhar do telespectador, participa, de forma mais ou menos marcada, mais ou menos consciente, na formação da imagem e/ou do valor atribuído à informação e, por extensão, à estação de televisão que a propõe. Assim, formulámos a hipótese segundo a qual a cenografia de informação é um meio de as estações de televisão definirem uma imagem - a sua imagem de marca ou identidade -, exprimindo através dessa forma cénica (não-verbal) determinadas estratégias comunicacionais.

No sentido de evidenciar a evolução histórica dos cenários de informação televisiva, foram realizadas entrevistas em profundidade a alguns dos principais responsáveis pela con-

\footnotetext{
${ }^{1}$ Uma consulta às notícias editadas pela Marktest sobre o share mensal dos programas das três estações generalistas portuguesas (www.marketest.com, retirado a 1 de Janeiro de 2009), indica que os programas informativos de horário nobre, na generalidade, têm um share de cerca de $30 \%$ cada um.

${ }^{2} \mathrm{O}$ ticker é conhecido pelo espectador como rodapé, utilizado para passar, no fundo do ecrã, títulos de outras notícias do dia. Este vocábulo foi adoptado do vocabulário de economia, onde designa a informações das cotações de bolsa que correm no fundo do ecrã.

${ }^{3}$ E restantes programas de informação, distinguindo-se da cenografia de produção de outros programas televisivos não informativos: teatro, ficção, variedades...
} 
cepção dos mesmos ${ }^{4}$, desde 1957. Com estas entrevistas, pretende-se saber, além das datas e alteração de cenário, o que está por detrás de uma mudança de cenário, bem como os objectivos a alcançar com cada um deles. Além disso, procedeu-se já à consulta de imagens de Arquivo da RTP e da SIC. ${ }^{5}$ A análise desta documentação processou-se a partir de três dimensões analíticas: a) caracterização da cenografia e da sua relação com as inovações tecnológicas; b) o cenário e a relação "imaginada" com o público; c) o contexto audiovisual português.

\section{0 noticiário televisivo e a evolução da cenografia de informação em Portugal}

A análise produzida permitiu-nos chegar à caracterização de quatro grandes períodos da evolução histórica da cenografia de informação televisiva em Portugal ${ }^{6}$. Apesar de a evolução ser, obviamente, um contínuo, o estabelecimento de datas-fronteira de transição permite-nos sintetizar de forma clara as etapas da evolução da televisão. Esta divisão propõe delimitar contextos distinguindo-os pela (pre)dominância de determinados conceitos ou actores com implicações directas para a forma como se encena a informação.

\section{A Era da Técnica: à procura de uma linguagem (1957-1974)}

A televisão pública portuguesa inicia as emissões regulares a 7 de Março de 1957, após experiências diversas, nomeadamente a cobertura da visita oficial da Rainha Isabel II a Portugal. Esta visita determina por um lado o próprio aparecimento da televisão portuguesa e por outro a importância das notícias na televisão (Teves ${ }^{7}$, Entrevista: 3 Abril 2008). A RTP surge em Portugal durante o período salazarista, como televisão única sob controlo directo do governo. Este aspecto condiciona fortemente a forma e o conteúdo da programação e, obviamente, dos noticiários.

No início, a cenografia aplicada à informação é muito simples devido em grande parte à exiguidade do primeiro estúdio no Lumiar, de cerca de $18 \mathrm{~m}^{2}$, partilhado com outros programas. Foi um recanto desse estúdio único, designado "a Caverna”, que foi transformado em estúdio de informação. Essa precariedade implicava a desmontagem dos cenários no final da emissão, a montagem dos da emissão seguinte e a permanência de duas equipas de cenografia 24 horas por dia (Polainas, 1998). Estas equipas traba-

\footnotetext{
${ }^{4}$ RTP: António Polainas, Vasco Hogan Teves, António Casimiro, José Alberto Carvalho. SIC: Pedro Dias, Eduarda Silva, Vítor Duarte, Maria João Ruela, Luís Costa Ribas, Agostinho Ribeiro, Clara de Sousa. TVI: António Rego.

${ }^{5}$ Uma segunda fase do projecto centrou-se na análise dos efeitos da cenografia informativa sobre o processamento da informação.

${ }^{6}$ Partimos de uma primeira caracterização em quatro eras, referida por Polainas (1998) - Era dos Engenheiros (1926-anos 40), Era dos Realizadores (anos 1950-60 a 1970), Era dos Jornalistas (1970-1990) e Era do Marketing (a partir dos anos 1990), procurando introduzir novos conceitos e estender a análise até à actualidade. António Polainas, arquitecto e actual subdirector de Artes Visuais da RTP, trabalha no departamento de cenografia há trinta anos. É autor da tese de Mestrado em Teoria da Arquitectura, intitulada Cenografia de televisão em Portugal (1957-1992).

${ }^{7}$ Vasco Hogan Teves, profissional da RTP já reformado, ligado à informação de 1957 a 1974, foi Director do Telejornal entre 1971 e 1974.

${ }^{8}$ Progressivamente chegou-se a uma optimização dos processos e definiu-se mesmo uma tipificação de cenários (Polainas, 1998). As equipas de execução foram reduzidas até serem extintas nos anos 90.
} 


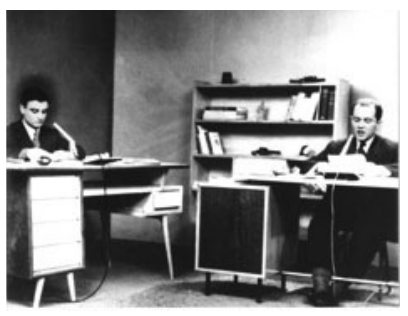

lhavam de forma artesanal e asseguravam todas as fases do processo de cenografia (concepção, execução, montagem, desmontagem, readaptação de elementos...).

Tal como noutras estações de televisão da época, a cenografia de informação na RTP debuta como a "mera" criação de uma cena ou décor para a transmissão das notícias: basicamente, um fundo neutro (cortina ou ciclorama), uma secretária e uma cadeira para o locutor, um microfone para a captação de som. Lembremos que o início da transmissão das notícias na televisão corresponde também ao início da própria televisão como media, assistindo-se assim à procura de uma linguagem própria ${ }^{9}$, ao longo de experimentações e adaptação de técnicas e linguagens do teatro, do cinema ou da rádio.

A primeira emissão de um espaço noticioso ocorre aquando do nascimento da estação de televisão pública, pelas $22 \mathrm{~h} 00$, meia hora depois do início das emissões regulares da RTP (Teves, 2007) ${ }^{10}$.

Do ponto de vista cenográfico, esta fase fica marcada pela influência do teatro, nomeadamente na disposição das câmaras «em linha», frente a frente com o cenário, com uma posterior adaptação às técnicas de realização do cinema (Polainas, 1998). A BBC, a CNL (EUA) e a RTF (França) são as estações que servem de inspiração a Marcelo de Morais, arquitecto responsável pelo desenvolvimento da cenografia da RTP, cujo «objectivo prioritário» é «adaptar a estrutura da cenografia da BBC à nossa realidade» (Polainas, 1998: $120)^{11}$. Em 1959, Marcelo de Morais cria o termo cenografista, que ainda hoje designa o «profissional de cenografia para televisão» (Polainas, 1998: 122), aquele que concebe e cria os cenários de televisão. Esta área é a mais desenvolvida na jovem RTP, contando com uma grande equipa multidisciplinar de cerca de setenta elementos logo nos anos 1960 .

A 18 de Outubro de 1959, pelas 20h30, o Jornal de Actualidades dá lugar ao Telejornal (Teves, 1998), nome que se mantém até à actualidade, ao mesmo tempo designação e formato específico do jornal televisivo de horário nobre. A sua duração fixa-se em meia hora ${ }^{12}$ e é definido um alinhamento diferente do anterior, reservando mais espaço e tempo para os locutores ${ }^{13}$, inclusive através dos textos, pois “escrevia-se para os locutores” (Teves, Entrevista: 3 Abril 2008). Há a preocupação de intercalar a informação e a locução em estúdio para criar um certo dinamismo e evitar grandes blocos de imagem ou uso repetido de imagens. Em suma, cria-se um cenário que distingue

\footnotetext{
${ }^{9}$ A procura do domínio da técnica audiovisual em detrimento do aspecto cénico levou a que Polainas caracterizasse este período como a Era dos Engenheiros.

${ }^{10}$ Os antecessores do Telejornal são o Noticiário, o Jornal RTP e o Jornal de Actualidades.

${ }^{11}$ Logo em 1936, a BBC contratou «a primeira equipa de cenografia de televisão, formada por dois profissionais do cinema e do teatro" (Polainas, 1998: 23), levando à criação do tv designer, nos anos 50, profissional que concilia os conhecimentos de arquitectura, cultura geral e realidade televisiva.

${ }^{12}$ Trinta minutos é, durante muito tempo, a duração do Telejornal, seguida também pelas televisões privadas no seu início; antes de 1974 a duração chega a ser controlada ao minuto.

${ }^{13}$ Até 1975 os redactores não podem ser considerados jornalistas por não estarem inscritos no respectivo sindicato, por isso são designados por locutores; esta questão atesta assim a dificuldade de aceitação pela profissão do novo meio jornalístico que é o jornal televisivo.
} 
definitivamente o jornal de televisão das actualidades do cinema. Esta procura de um estilo para o Telejornal é discutida e experimentada pelos realizadores (Fernando Lopes e Hélder Mendes), o Chefe de Redacção e mesmo alguns dos locutores. Entra-se, assim, na Era dos Realizadores: as dificuldades técnicas iniciais já estão ultrapassadas e decide-se apostar na imagem e qualidade dos programas com a descoberta das potencialidades do mercado publicitário. Quem toma conta da produção televisiva são os realizadores e cenografistas. O desenvolvimento da cenografia toma então outras proporções, chegando a uma desejada autonomia no seio do panorama televisivo: "As técnicas de cenografia e de realização desenvolveram-se de forma a criarem regras próprias, que vieram a influenciar a "linguagem da televisão" "(Polainas, 1998: 147).

Os primeiros tempos do Telejornal demonstram inovação na cenografia, introduzindo o planisfério e o logótipo da estação. O planisfério, com algumas mudanças ao longo dos tempos, vai-se mantendo, pois é um elemento associado à informação (Polainas, Entrevista: 16 Janeiro 2008) ${ }^{14}$. A concepção é partilhada por Marcelo de Morais, Octávio Clérigo e, mais tarde, António Casimiro ${ }^{15}$. Em cima da mesa (desenhada para o Telejornal), além do microfone, está um telefone para receber notícias de última hora ${ }^{16}$. Posteriormente, introduzem-se transparências de fundo (por um sistema de retroprojecção de imagens fixas) por detrás do locutor, para difundir imagens ou texto.

\subsection{A introdução do videotape e a cobertura dos eventos internacionais}

Uma viragem tecnológica importante na história da RTP dá-se em 1964, com o intercâmbio noticioso com a Eurovisão e a introdução do videotape, que permite a divulgação de notícias do próprio dia ${ }^{17}$. Esta inovação permite criar uma primeira versão do que é hoje o pictograma: a projecção de uma imagem fixa ao lado direito do pivot. Segundo Polainas, esta inovação, que consegue transmitir a notícia à medida que acontece, acabou por cativar o olhar do espectador para a informação, olhar que antes se dirigia aos musicais e teatros emiti-

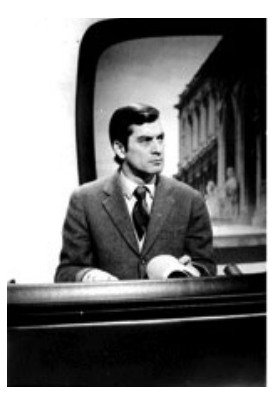
dos pela televisão. A difusão de factos internacionais marcantes, nos anos 1960, como o assassinato de Kennedy, a Guerra do Vietname ou o Maio de 68 têm um impacto grande. "O público começa a aperceber-se de que estamos muito mais próximos do mundo do que estávamos anteriormente" (Teves, Entrevista: 3 Abril 2008). Esta mudança origina uma afirmação da importância dos programas de informação e consequentemente uma reorganização da programação e dos meios técnicos, a mobilidade de repórteres, os directos.

\footnotetext{
${ }^{14}$ A representação do planisfério, mais ou menos estilizado ou colorido, é uma constante em quase todos os jornais televisivos, nacionais ou internacionais, e talvez o elemento cenográfico mais antigo, comum e transversal à informação televisiva. Por isso é, talvez, o ícone da informação em televisão, o símbolo do Telejornal, o símbolo da própria cenografia de informação. Ele representa a própria essência da informação televisiva: do mundo para o mundo, em directo.

${ }^{15}$ António Casimiro é cenógrafo e trabalhou de 1958 a 1995 na RTP.

${ }^{16}$ Este objecto que devia assegurar a transmissão em directo de notícias de última hora é transformado em mero adereço pela conjuntura política de controlo da informação pelo Governo de então (Teves, 2007), ou seja, o telefone não está ligado para não dar azo à difusão de notícias não controladas.

${ }^{17}$ Notícias da Europa e também dos EUA. Até então só havia o filme, cujo tratamento atrasava a difusão actualizada das notícias (Teves, Entrevista: 3 Abril 2008).
} 


\section{A Era dos Jornalistas: do fim da censura à televisão privada (1974-1980)}

O 25 de Abril de 1974 participa desta transformação da RTP: «tendo a área de informação passado pelas convulsões mais profundas, como o afastamento de pessoas anteriormente ligadas à programação (...), [surgindo igualmente um] novo formato de apresentação de notícias» com a introdução de debates no Telejornal e com programas independentes (Polainas, 1998: 206). É, nesta altura, resolvida a distinção entre locutores, redactores e jornalistas, contribuindo para a afirmação da profissão de jornalista no meio televisivo. Este período é marcado por mudanças constantes também na cenografia e no formato do Telejornal. É esta crescente importância atribuída à reportagem jornalística que nos leva a caracterizar este novo período como Era dos Jornalistas ${ }^{18}$. Os novos estúdios do Lumiar, inaugurados em 1977, permitem a cedência de um estúdio unicamente dedicado à informação, onde as mesas dão lugar às «bancas modulares» sendo, assim, possível adequar o cenário ao tipo de programa e ao número de convidados. «A planificação modular passou a ser uma referência para o espaço cenográfico. Todavia, a realização manteve-se simples e linear» (Polainas, 1998: 207).

\subsection{A chegada da cor}

A introdução da cor na televisão vem abrir novas perspectivas à cenografia, permitindo novas combinações, embora também potencie limitações: materiais utilizados na cenografia e logótipos, a iluminação, o vestuário dos pivots, a maquilhagem, etc.

Nos inícios dos anos 80, a área de cenografia opera uma reformulação cenográfica com implicações para a realização e a composição da imagem considerada ideal para a informação (Polainas, 1998): a triangulação introduzida na RTP por Manuel Tomás (Casimiro, Entrevista: 16 Abril 2008). Com os elementos cenográficos dispostos em triângulo, conseguia-se a captação dos vários intervenientes de frente bem como de distintos cenários, graças à mobilidade das câmaras e aos novos ângulos de captação de imagem, abandonando-se a tradicional disposição em linha. A escolha de cores, preocupação inerente ao trabalho do cenografista, assume agora grande importância, pois tudo deve transmitir uma mensagem determinada. No Telejornal a palete de cores deve transmitir sobriedade e credibilidade, associada a uma imagem moderna e informal, não descurando o destaque do pivot através da iluminação, com aplicação de cores no cenário distintas do seu tom de pele, de modo a atrair para ele a atenção do espectador. Para tal, a RTP decide escolher o azul (Polainas, 1998).

Em Fevereiro de 1985, o cenário informativo aposta numa simplicidade com um fundo cinzento quebrado por uma linha vermelha e o símbolo da RTP. Mas logo em Junho, Carlos Fino apresenta o Telejornal diante de um fundo azul e cinzento com um globo iluminado a azul à esquerda do pivot.

A inauguração do novo centro de emissões da RTP na Avenida 5 de Outubro, em 1986, aumenta substancialmente o espaço dedicado à informação: passa a haver dois

\footnotetext{
${ }^{18}$ Polainas (1998) utiliza esta designação para caracterizar um período anterior. E se é verdade que já antes do 25 de Abril se registava uma crescente importância do papel dos jornalistas na informação televisiva, consideramos que em Portugal só com a quebra da censura esse fenómeno ganhou consistência.
} 


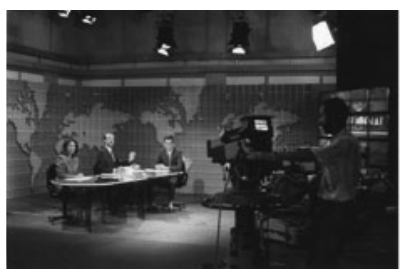

estúdios e a redacção ocupa vários andares (Polainas, 1998). Nesta altura a tecnologia invade os estúdios de informação, o que levou a dizer-se que «a Informação da RTP entrava numa nova era» começando a ser habitual o uso do directo no Telejornal ${ }^{19}$ (Teves, 2007). Esta tecnologia permitia integrar elementos como os ecrãs em background, a janela "como extensão do próprio estúdio criando uma sensação de profundidade e permitindo a ilusão de um espaço aberto para o exterior», ultrapassando assim a limitação imposta pela exiguidade dos estúdios que não davam azo à criação de cenografias muito elaboradas (Polainas, 1998). Retomou-se o uso do planisfério de design moderno e estilizado, aplicado em Maio de 1986, Abril de 1987, Março de 1988, Novembro de 1988 e Fevereiro de 1991. As cores predominam no azul, branco e cinzento. Começa a apostar-se mais em infografia com a inserção do pictograma à direita e recorre-se ao pivot principal e ao pivot de Desporto.

Nesta transição para a década de noventa, "o Telejornal tornava-se o expoente máximo da Informação» (Polainas, 1998: 209) e ritual diário nacional, repercutindo-se na cenografia do programa. O destaque da banca de apresentação, os computadores, monitores e outras tecnologias, o pivot como vedeta, foram os novos elementos de uma cenografia que se pautava pela transmissão do conceito de transparência noticiosa através do uso de acrílicos. Surge uma parafernália de tecnologia com monitores, «televisores de grande formato (ou mamute), videowall, janelas electrónicas, vidiwall, composições conjugando janela electrónica com vidiwall e finalmente a utilização simultânea de todos eles: monitores de pequeno e grande formato, vidiwall e janela electrónica» (Polainas, 1998: 210). O final deste período anuncia a mudança do contexto audiovisual português com a abertura do espaço audiovisual à concorrência, previsto desde finais dos anos $1980^{20}$, pondo fim a 35 anos de monopólio da RTP.

\section{A Era do Marketing: competitividade na e pela informação (1992-2000)}

A 6 de Outubro de 1992 iniciam-se as emissões da Sociedade Independente de Comunicação. Na SIC, o Jornal da Noite quis pautar-se pela diferença (Silva ${ }^{21}$, Entrevista: 17 Abril 2008). O logótipo composto por "cores quentes" transmitiu para a cenografia de informação da estação de Carnaxide essa mesma imagem. Pedro Dias ${ }^{22}$ (Entrevista: 27 Fevereiro 2008) caracteriza os primeiros cenários, da autoria de Tomás

\footnotetext{
${ }^{19}$ Este facto faz mudar os hábitos dos políticos, que marcavam as suas conferências de imprensa para o horário do Telejornal (Teves, 2007).

${ }^{20}$ Pela mão do governo liderado por Cavaco Silva, através da segunda revisão constitucional, onde consta que «a Alta Autoridade para a Comunicação Social emite parecer prévio à decisão de licenciamento pelo Governo de canais privados de televisão, a qual, quando favorável à outorga de licença, só pode recair sobre candidatura que tenha sido objecto de parecer favorável» (Lei Constitucional n. ${ }^{\circ}$ 1/89 de 8 de Julho, Segunda Revisão da Constituição), cumprindo o programa eleitoral de 1987 do PSD (Santos, 2002).

${ }^{21}$ Eduarda Silva, autora de cenários para a SIC de 1992 a 2002, colabora actualmente com a estação em regime de freelancer.

${ }^{22}$ Pedro Dias é co-fundador da SIC.
} 
Taveira, como «opacos, com cores, linhas e ângulos quebrados» ${ }^{23}$. O importante era demarcar a SIC da RTP com «mais cor e mais luz».

A inovação passa ainda por mostrar o que está por detrás do Jornal da Noite da SIC: a redacção, opção que foi posteriormente seguida pelos canais concorrentes. Este open space participa da mensagem institucional que podemos designar por fábrica de notícias, 'local onde se fabrica algo'. Ou seja, a transmissão da notícia do próprio local onde é feita e por quem é feita. A esta junta-se a metáfora da transparência, dado que a notícia é transmitida pelos que a escrevem sem intermediários. Esta noção participa da imagem de marca da SIC e contrapõe-se como "crítica” à imagem algo asséptica do "estúdio" do Telejornal "rtpiano", imagem demasiado televisiva em contraste com a imagem da redacção jornalística, esta sim autenticamente jornalística.

Conforme admite Casimiro (Entrevista: 16 Abril 2008), «a SIC causou um impacto muito grande», tendo alertado então para a necessidade de ser a «informação um dos grandes sectores a mexer» na RTP para fazer face à concorrência.

No ano seguinte, a 20 de Fevereiro de 1993, Clara de Sousa anuncia, no programa «Informação 4», da Televisão Independente (TVI), o nascimento do novo canal, sob um fundo que oscila entre as cores claras e o vermelho-escuro, e uma mesa de granito. A análise da cenografia seguinte da TVI (1994) ilustra bem a importância da clareza da intenção comunicacional ou da imagem corporativa que a cenografia deve traduzir. Os primeiros jornais televisivos têm uma aparência 'sóbria', uma só mesa, não há visão para a redacção. Por detrás do/a pivot, um cenário básico de cor cinzenta favorecia a concentração no apresentador; o único elemento de contraste era a mesa em vermelho mate e uma parede de ecrãs.

A resposta da RTP passa por uma nova mudança, onde a constância do planisfério alterna com uma parede de ecrãs. A mesa a que se senta Henrique Garcia em Maio de 1993 é completamente de vidro. Durante o período deste cenário, alteram-se e aperfeiçoam-se os grafismos e, com falta de uma estrutura como a da redacção da SIC, a RTP mostra também a sua através do pivot que por aí caminha com uma antevisão das notícias.

Posteriormente, assiste-se na TVI a uma procura de identidade cenográfica até à reformulação de 2000, já com a Media Capital, com uma imagem fortemente marcada pelo trabalho de Tomás Taveira, autor do actual cenário. As mudanças ${ }^{24}$ foram surgindo timidamente com alguns apontamentos de cor até à reestruturação com José Eduardo Moniz, no final dos anos noventa. A registar duas transformações físicas evidentes, com a criação do estúdio com o plateau em baixo e a redacção à sua volta e numa varanda superior, em que a mutação mais evidente era a mesa do pivot. A par disso, registaram-se algumas evoluções no grafismo da TVI, em quase tudo semelhantes ao que o espectador vê agora, nomeadamente a gestão das cores básicas da estação: amarelo, azul e vermelho. Sem uma regra aparente, alternava a apresentação com ou

\footnotetext{
${ }^{23}$ Recuperado em 2008, Junho 24, de http:/ / www.youtube.com/watch?v=aBNuKtogREM

${ }^{24}$ Sobre as mudanças de cenografia informativa da TVI pouco mais se pode dizer tendo em conta os poucos dados existentes sobre a estação, concretamente sobre esta temática; até agora, e apesar de várias tentativas, ainda não foi possível entrevistar responsáveis desta área na TVI.
} 


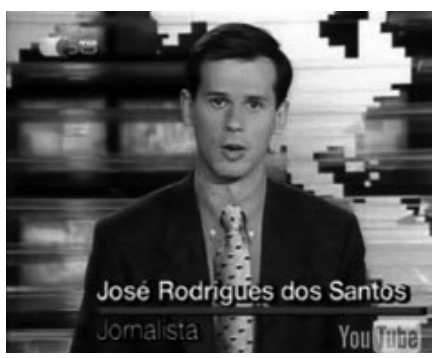

dois pivots, rodeados dos elementos acima descritos: logótipo da estação, pictograma ${ }^{25}$, títulos e rodapés com informação das várias outras notícias.

A estratégia adoptada pela SIC garante-lhe a conquista das audiências três anos depois do seu arranque (Santos, 2002), graças à aposta na informação (Lopes, citado em Santos, 2002; Traquina, 1997), sustentada em fontes que não as oficiais (Santos, 2002).

No seguimento da criação da SIC e da TVI, a RTP elaborou uma proposta de alteração de cenários, radicalmente diferente dos da concorrência (em 1995 e 1997), para «entrar num caminho em que se recuperou o rigor, a sobriedade, num estúdio onde não há um bocadinho de pintura, com utilização de madeira e grafismo como parte integrante, com organização geométrica, com um sentido e uma ordem»(Polainas, Entrevista: 16 Janeiro 2008). Manteve-se a imagem do planisfério, acrescentaram-se alguns dos elementos tecnológicos usados pela SIC (ecrãs), porém com muito menos destaque (50 Anos, 50 Notícias $^{26}$ ). O tratamento dos elementos gráficos assume uma clara importância e um papel determinante na criação de uma imagem de marca que distinga a RTP das outras televisões, a fim de retomar a audiência perdida para a SIC. A alteração de Janeiro de 1995 encobre os ecrãs televisivos com barras horizontais de acrílico transparente com planisfério recortado e parede de ecrãs por trás. Ao centro, a mesa branca e redonda que contorna um globo terrestre rodeado de ecrãs. O pictograma passa agora a ser apresentado à esquerda. Um videowall à direita dá ainda possibilidade de mudar o cenário por detrás do pivot.

Esta mutação evidencia a transição para a Era do Marketing em que a programação está submetida aos estudos de mercado e indicadores de audiências. Regista-se uma alteração nas temáticas e alinhamento do Telejornal, preenchido com os chamados faitdivers que prendem a atenção do espectador, alargando gradualmente os noticiários para cerca de hora e meia ${ }^{27}$ (Polainas, Entrevista: 16 Janeiro 2008). O jornal televisivo aproxima-se mais do programa (de entretenimento) que do bloco de actualidades dos primórdios. Esta mutação verifica-se em todos os noticiários nacionais: cenograficamente falando, regista-se a integração de «elementos "perturbadores" para desviar e distrair a atenção do espectador mantendo-o preso ao ecrã: luzes, monitores espalhados pelo cenário, formas coloridas, etc.» (Polainas, 1998: 489). O arquitecto (1998: 448) afirma mesmo que:

Ao rigor desprovido de protagonismo dos serviços noticiosos do passado sucede o 'espectáculo informativo' dos nossos dias, no qual desfilam convidados (especiais e não tão especiais), pleno de cores e de luzes, por entre os quais vão espreitando alguns tímidos apontamentos noticiosos mais sérios.

\footnotetext{
${ }^{25}$ Destas, destaca-se o pictograma que indicava a sequência das notícias numa antecipação da informação e onde podia ler-se "agora, depois, a seguir".

${ }^{26}$ Recuperado em 2008, Abril 10, de http://ww1.rtp.pt/wportal/informacao/50anos_50noticias/

${ }^{27}$ Este prolongamento dos jornais televisivos portugueses prende-se também com a possibilidade de introduzir intervalos publicitários em emissões mais longas, o que confirma a primazia do marketing neste período.
} 
Em 1997, "para contrariar o efeito de erosão» (Santos, 2002: 96), a SIC renova os seus cenários informativos ${ }^{28}$. No Jornal da Noite, é sobretudo a nível gráfico que se registam mais alterações: nos formatos e cores do logótipo da estação, rodapés, títulos, oráculos, tickers e pictogramas (por vezes com o uso de um plasma ao lado do pivot).

Em 2000 há uma nova mudança da RTP com uma mesa oval cinzenta ao centro sob um estrado com luzes vermelhas ou azuis. Os desktops dão lugar aos portáteis e os grafismos, incluindo o pictograma, são envolvidos em cor laranja. Atrás dos pivots, uma parede de vidis, sendo os da esquerda, que se vêem com o pivot de Desporto, ladeados por colunas luminosas a azul. Introduz-se, ocasionalmente, a apresentação em pé.

A RTP enfrenta o desafio da inovação e, já perto do século XXI, muda para um cenário bem próximo do actual ( 50 Anos, 50 Notícias $^{29}$ ). O novo estúdio integra a redacção, «não há um espaço fechado, tudo é um espaço de trabalho» (Polainas, Entrevista: 16 Janeiro 2008), situado no r/c do edifício da Avenida 5 de Outubro. Insiste-se novamente na apresentação ocasional em pé. A mesa do pivot é uma das grandes inovações, já que pode rodar a 180 graus, permitindo uma maior variação de cenários.

\section{A Era do Virtual: novamente à procura de uma linguagem própria (2001-)}

O novo milénio traz transformações tanto ao nível tecnológico (generalização do uso do virtual) como cenográfico em todas as televisões. Permutam-se directores e pivots.

Em relação à SIC, Silva (Entrevista: 17 Abril 2008) fala em “época Rangel” e “pós-Rangel” " ${ }^{30}$, com a entrada de Alcides Vieira para a direcção de Informação e o termo da colaboração de Tomás Taveira ${ }^{31}$. Importava haver aqui uma demarcação da imagem anterior, com uma nova cenografia ${ }^{32}$ : fecha-se a vista sobre a redacção com um videowall onde podem ver-se inúmeros canais em simultâneo. Abandonam-se os ecrãs e a SIC entrega-se ao virtual ${ }^{33}$ e ao croma key numa redacção com a janela fechada.

A 31 de Março de 2004, nasce «a nova RTP», conforme o anúncio de José Rodrigues dos Santos na abertura do Telejornal nas novas instalações da Avenida Marechal Gomes da Costa. O estúdio, com cerca de $1000 \mathrm{~m}^{2}$, foi «concebido e projectado pelas unidades internas de cenografia da RTP e combina as técnicas de cenografia de produção e informação respondendo assim à necessidade de concentrar meios cenográficos num espaço único, individualizar ambientes para produção semanal de vinte e três programas diferentes, possibilitar uma flexibilidade tal que permita a mudança diária de cenários para dez programas, aliada à presença de um espaço redactorial para cerca de setenta jornalistas ${ }^{34}$. Inicia-se o uso do virtual em notícias de grande impacto, em que o pivot apresenta as notícias de pé.

\footnotetext{
${ }^{28}$ «O cenário incluía displays de informação ao lado e por detrás do pivot, com informação suplementar, o que criou a imagem de marca do canal. Ainda não era um ecrã idêntico ao das múltiplas janelas da página da Internet, com um oráculo a correr no rodapé, como ocorreria já na passagem para o novo século, mas aproximava-se disso» (Santos, 2002: 96).

${ }^{29}$ Recuperado em 2008, Abril 10, de http://www.rtp.pt/wportal/informacao/50anos_50noticias/

${ }^{30}$ Emídio Rangel foi director-geral da SIC, ocupando o mesmo cargo na RTP a partir de 2001.

${ }^{31}$ Dado que entretanto tinha, alegadamente, concebido cenários para o jornal televisivo da TVI.

${ }^{32}$ Eduarda Silva assume com Agostinho Ribeiro a autoria deste novo cenário.

${ }^{33}$ Uma primeira experiência de cenografia virtual é feita pela SIC em 1997, aquando da emissão especial das eleições autárquicas (Santos, 2002).

${ }^{34}$ Recuperado em 2008, Março 13, de http://www.rtp.pt/wportal/grupo/instalacoes4.htm
} 
Em Fevereiro de 2006, a SIC apresenta o Jornal da Noite com cenário remodelado. Agora, o espectador pode ver, alternadamente, a imagem de um globo terrestre em movimento rotativo e uma ilustração da notícia, usando o virtual. A apresentação em pé também figurava neste novo modelo, no lado oposto à mesa do pivot. Alcides Vieira reitera que o que importa é «melhorar, em muito, a qualidade da informação», através do seu fortalecimento com gráficos ou imagens, e apostando na predominância do vermelho, azul e branco (2006, Fevereiro 17). Porém, esta cenografia revelou-se problemática, dado que o movimento permanente era factor perturbador e a imagem do globo era constantemente substituída por imagens relacionadas com as notícias, levando à perda da identidade daquele jornal (Duarte ${ }^{35}$, Entrevista: 26 Junho 2008).

Esta apresentação das evoluções das três televisões torna ainda mais clara a luta pelas audiências e a resposta "taco a taco" às alterações verificadas em cada uma. $\mathrm{Na}$ Era do Virtual, que prolonga a Era do Marketing, estas transformações traduzem a procura de inovação técnica para conseguir uma maior atracção do telespectador.

\section{Tridimensional, virtual e real}

A SIC utilizou pela primeira vez a cenografia virtual fora das telas verdes (croma key) no Jornal da Noite de 19 de Novembro de 2007, com a tridimensionalidade. De um, passa-se para dois pivots e "repesca-se" a abertura da janela para a redacção. O virtual permite contornar os problemas de espaço, uma variação mais rápida dos cenários, ainda que não à velocidade desejada, ao invés do cenário real que exige tempo de montagem e desmontagem (Dias, Entrevista: 27 de Fevereiro de 2007).

Esta transformação resulta de um profundo trabalho de reflexão e de concepção de uma nova imagem para a informação da SIC e que passou pela criação da Bloom Graphics, em Março de 2007, empresa que reúne as áreas de cenografia, design gráfico e imagem gráfica de todos os canais SIC. Esta transformação mexeu com a organização espacial da redacção, da central técnica e do estúdio, com a forma de trabalhar dos jornalistas ${ }^{36}$, mas também com os elementos gráficos que foram reduzidos em tamanho e em quantidade (Duarte, Entrevista: 26 Junho 2008). O estúdio passa a ter três espaços: a mesa ao centro, o "palco" virtual à esquerda e à direita um espaço dedicado aos especialistas. Contudo, o cenário virtual parece acrescentar pouco ao que se pretende informar. Tome-se como exemplo a edição de 19 de Março de 2008: numa notícia acerca da subida dos preços do petróleo adicionam-se, ao lado do pivot, alguns barris virtuais ${ }^{37}$. Trata-se mais de um elemento ilustrativo do que informativo e de uma tecno-

\footnotetext{
${ }^{35}$ Vítor Duarte é actual director da Bloom Graphics, trabalha na área gráfica da SIC desde 1992; é um dos autores da última transformação cenográfica da SIC.

${ }^{36}$ A redacção passa a organizar-se num agrupamento concêntrico partindo de um pólo central ou in-take que processa a chegada da informação, estando os jornalistas distribuídos por áreas temáticas e já não por equipa de programa informativo. Nesta lógica o próprio acto de redacção da peça é alterado dado que o jornalista escreve a notícia para si mas também para o pólo central, podendo a notícia ser utilizada noutro bloco informativo. Os profissionais passaram a colocar-se de costas para o estúdio, deixando à vista os monitores dos computadores (Duarte, Entrevista: 26 Junho 2008).

${ }^{37}$ Recuperado em 2008, Maio 3, de http://sic.aeiou.pt/online/noticias
} 


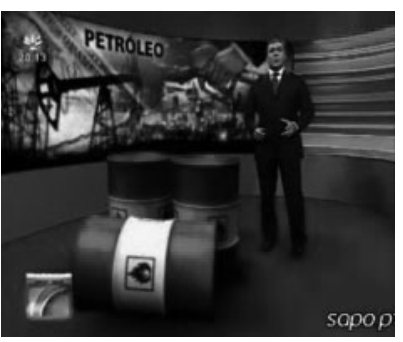

logia em experimentação ou adaptação. A composição da imagem é também um novo desafio para os realizadores, dado o tamanho do palco virtual, parecendo por vezes o pivot ficar muito pequeno.

Apesar do virtual, a concorrência é bem real, levando à consequente transformação da informação num produto comercial cujo valor está nas audiências que consegue gerar (Polainas, Entrevista: 26 Janeiro 2008).

Inevitavelmente, a RTP mudou o seu grafismo a 26 de Maio de 2008, sendo acusada de plágio pela SIC: a estação pública apostou em cores mais quentes no seu genérico, deixando de parte os rodapés corridos que deram lugar a frases fixas. Adaptando a cenografia ao novo grafismo, em Dezembro último, o aspecto da redacção background do Telejornal muda. Com um aspecto futurista, a RTP aposta numa mesa imponente e de design vanguardista.

Esta última mutação cenográfica da SIC põe em evidência um aparente paradoxo: ao mesmo tempo que se cria um "palco virtual” para dar todo o espaço à nova tecnologia - o tridimensional virtual -, redimensiona-se a cenografia convencional, reintegra-se a redacção no estúdio de forma mais cenografada (para que o que seja visto pelo telespectador seja mais pertinente e mais atractivo) através de uma reorganização total do espaço físico da redacção e do estúdio. O virtual comanda o concreto. Podemos talvez falar de uma nova Era dos Engenheiros ou, pelo menos, de uma tecnologização da informação. É interessante verificar que os autores desta transformação são maioritariamente designers gráficos e de equipamentos. A técnica e o design primam sobre o conteúdo.

\section{Conclusão: Porquê mudar de cenário informativo?}

Ao longo da evolução histórica dos jornais televisivos das três televisões generalistas nacionais, aparecem como principais razões de mudança de cenografia a inovação tecnológica e a decisão da direcção. De facto, a introdução de novos dispositivos tecnológicos obriga a repensar a cenografia, seja por pequenas adaptações seja por profundas transformações ao nível dos materiais, das cores, da iluminação, da relação da redacção com o estúdio e, consequentemente, da relação com o telespectador. A direcção da estação ou a direcção de informação são na maioria das vezes quem desencadeia as mudanças, para imprimir a sua marca própria, para fazer face à concorrência e reconquistar audiências ou para renovar o "visual" ". Muitas vezes são também os cenografistas quem sugere e concebe alterações para encontrar soluções mais equilibradas, mais operacionais, mais "conseguidas".

As alterações efectuadas à cenografia, nomeadamente nos seus aspectos gráficos, são decididas, em muitos casos, em resposta a críticas ou protestos (dos telespectadores

\footnotetext{
${ }^{38}$ Em período de monopólio "rtpiano", havia os "mapas-tipo" recordados por Teves (Entrevista: 3 Abril 2008) e Casimiro (Entrevista: 16 Abril 2008), que ditavam a mudança dos cenários de dois em dois anos.
} 
ou dos críticos ${ }^{39}$ ) ou mesmo ajustes a problemas constatados internamente. Durante a nossa pesquisa não foi possível, ainda, determinar de que forma é tratada esta informação e por quem, se existem estudos sistemáticos da recepção dos telespectadores da RTP, SIC e TVI, embora existam referências a estudos pontuais. Este facto vem ao encontro do que já foi constatado noutras áreas em que a cenografia assume a mesma importância (como as exposições em museus ${ }^{40}$ ), onde a reflexão sobre a linguagem própria da cenografia não merece uma atenção sistemática e continuada e parece não ter eco junto dos comanditários. Isto deve-se em parte às próprias características do processo de concepção cenográfica e ao estatuto da cenografia e dos cenografistas enquanto profissionais. Situada a meio caminho entre arte e técnica, entre arquitectura e design, entre arte de concepção do espaço e processo artesanal de fabrico de dispositivos, a cenografia padece, na televisão como nos museus, do reconhecimento que lhe é devido e que, paradoxalmente, lhe é de facto acordado pelos meios que as estações nela investem. Um aspecto que pode justificar em parte esta discrição da cenografia é o facto de ela ser, no fundo, “a receita secreta" da televisão, a "alma do negócio" da diferenciação e da imagem, donde deve permanecer secreta ${ }^{41}$.

Qual será o impacto desta (nova) relação de forças no estúdio sobre os profissionais da informação, por um lado, e sobre os telespectadores, por outro?

Em Portugal, esta preocupação está por se manifestar. No entanto, a investigação na área da comunicação tem procurado documentar a forma como os espectadores alteram a sua atenção em função de uma variedade de condições de visionamento, tendo como base a teoria da atenção selectiva de Broadbent (citado por Warshaw, 1978) que afirma que o processamento da informação está naturalmente restringido por uma filtragem sensorial da atenção que permite somente a um número limitado de estímulos aceder à memória de longo prazo. Alem Warshaw, também Reese (1981; 1983), Drew e Grimes (1987), Grimes (1991), Moore, Burton e Myers (1996) e Bergen, Grimes e Potter (2005) direccionaram a sua atenção para esta problemática.

No futuro, este projecto aponta para a caracterização do comportamento dos portugueses aquando do visionamento dos jornais televisivos de horário nobre, no sentido de elucidar os profissionais deste campo para as futuras concepções de cenários, tirando deles o máximo partido no que toca ao processamento da informação.

\footnotetext{
${ }^{39} \mathrm{O}$ aspecto actual da cenografia de informação, nomeadamente os grafismos, é alvo do olhar crítico de antigos profissionais, sendo qualificado de "um certo barroquismo" (Casimiro, Entrevista: 16 Abril 2008) e de "saturação de informação" (Teves, Entrevista: 3 Abril 2008); é criticado também o recurso à repetição de imagens e peças ao longo do dia, prática evitada nos primeiros anos da RTP, apesar das limitações técnicas da época.

${ }^{40}$ Entre os trabalhos que abordaram esta questão da cenografia de exposições de uma forma mais englobante referimos Veron, Levasseur (1985), Ethnographie d'une exposition, Centre Georges Pompidou/BPI, e Saraiva, Maria (2001), L'Environnement sensible dans les musées à caractère ethnologique. Approche interdisciplinaire des ambiances muséales. Thèse de Doctorat en Architecture, Université de Nantes.

${ }^{41}$ Daí a não publicação de projectos cenográficos, a não divulgação da estratégia comunicacional subjacente e mesmo a ocultação de certos dispositivos a profissionais em visita (aspecto referido por Polainas aquando de uma visita a estúdios de informação de uma televisão americana).
} 


\section{Bibliografia}

Bergen, L., Grimes, T. \& Potter, D. (2005). "How Attention Partitions Itself During Simultaneous Message Presentations". Human Communication Research, 31, 311-336.

Diciopédia 2008 [DVD-ROM]. Porto: Porto Editora, 2007. ISBN: 978-972-0-65263-8.

Drew, G. \& Grimes, T. (1987). “Audio-Visual Redundancy and TV News Recall”. Communication Research, $14,452-461$.

Feio, F. (2008, Maio 28). Diário de Notícias. Recuperado em 2008, Maio 28, de http://dn.sapo.pt/2008/05/28/ media/sic_acusa_de_copiar_grafismo_informa.html

Grimes, T. (1991). "Mild Auditory-Visual Dissonance in Television News May Exceed Viewer Attentional Capacity”. Human Communication Research, 18, 268-298.

Instituto António Houaiss de Lexicografia Portugal (2005). Dicionário Houaiss da Lingua Portuguesa. Lisboa.

Lei Constitucional n. ${ }^{\circ} 1 / 89$, de 8 de Julho (Segunda Revisão da Constituição).

Mendes, J. A., Santos Silva, C. \& Marques, N. (2007, 3 Março). “Cultivar ou entreter”. Única (suplemento do jornal Expresso). Recuperado em 6 de Março de 2008 de http://clix.semanal.expresso.pt/unica/artigo. asp? edition=1792\&articleid=ES248164.

Moore, M., Burton, J. \& Myers, R. (1996). "Multiple-channel communication: the Theoretical and Research Foundations of Multimedia”. Em D. H. Jonassen (Ed.). Handbook of Research for Educational Communications and Technology. Ohio, Estados Unidos da América: Ohio State University.

Polainas, A. (1998). “Cenografia de televisão em Portugal (1957-1992)". Tese de mestrado inédita, Universidade Lusíada.

Reese, S. (1983, Agosto). Improving Audience Learning from Television News through Between-Channel Redundancy. Comunicação apresentada no congresso anual da Association for Education in Journalism and Mass Communication, Corvalis.

Santos, R. (2002). "Dez anos de história da SIC (1992-2002)”. Observatório, 6, pp. 93-105.

Teves, V. H. (2007). RTP 50 anos de televisão. Recuperado em 2008, Fevereiro 13, de http://ww1.rtp.pt/ wportal/sites/tv/50anos/

Teves, V. H. (1998). História da Televisão em Portugal. Lisboa: TV Guia Editora.

Traquina, N. (1997). Big Show Media: Viagem pelo mundo do audiovisual português. Lisboa: Editorial Notícias.

Warshaw, P. (1978). “Application of Selective Attention Theory to Television Advertising Displays”. Journal of Applied Psychology, 63, 366-372.

2006, Fevereiro 17. "Informação da SIC vai mudar na segunda-feira". Diário de Notícias. Recuperado em 2008, Março 28, de http://dn.sapo.pt/2006/02/17/media/informacao_sic_mudar_segundafeira.html 